\title{
Performance Enhancement with Low Stress and Anxiety Modulated by Cognitive Flexibility
}

\author{
Doug Hyun Han ${ }^{1}$, Hyung Woo Park¹, Baik Seok Kee ${ }^{1}$, Churl Na1, Do-Hyun E. Na² and Leonard Zaichkowsky ${ }^{3}$ \\ ${ }^{1}$ Department of Psychiatry, Chung Ang University Medical School, Seoul, Korea \\ ${ }^{2}$ Department of Sports Marketing, DanKook University, Seoul, Korea \\ ${ }^{3}$ Education, Graduate Medical Science \& Psychiatry, Boston University, Boston, MA
}

\begin{abstract}
Objective The purpose of this study was to compare cognitive flexibility abilities, stress, and anxiety between starters and non-starter athletes.

Methods A total of 30 male professional-soccer and 40 professional-baseball athletes were recruited. Wisconsin Card Sorting Test (WCST) and Trail Making Test A \& B (TMT A \& B) were administered to assess cognitive flexibility during competition. The Korean version of the STAI form Y (STAI-KY) and Visual analogue scale for anxiety and stress were used to assess the anxiety and stress.

Results The starter group had better cognitive function (fewer perseverative errors and rapid TMTB times) $(\mathrm{Z}=3.32, \mathrm{p}<0.01 ; \mathrm{Z}=2.20$, $\mathrm{p}=0.03$, respectively) and lower stress and anxiety $(\mathrm{F}=4.34, \mathrm{p}=0.01 ; \mathrm{F}=6.61, \mathrm{p}<0.01$, respectively) during competition than the non-starter group.

Conclusion The better cognitive performances were negatively correlated with stress and anxiety. Current results suggested that cognitive flexibility would enhance human performance by modulation of the anxiety and stress during competition.
\end{abstract}

Psychiatry Investig 2011;8:221-226

Key Words Cognitive flexibility, Stress, Anxiety, Starter professional athletes.

\section{INTRODUCTION}

\section{Cognitive flexibility, stress in problem solving and anxiety}

When encountering a stressor, individuals endeavor to solve the problem, or avoid the stressor, or deal with it by using a variety of coping methods. ${ }^{1}$ One of these coping mechanisms is cognitive flexibility which is defined as the capacity to shift attention from one aspect of an object to another. ${ }^{2}$ It is similar to what Nideffer ${ }^{3}$ mentioned three of the subscales relate to an effective attentional style): broad external attentional focus (BET), broad internal attentional focus (BIT) and narrow attentional focus (NAR) and the other three subscales refer to ineffective attentional styles (Table 1): overloaded external focus (OET),

Received: November 17, 2010 Revised: February 10, 2011

Accepted: March 14, 2011 Available online: July 11, 2011

$\triangle$ Correspondence: Doug Hyun Han, MD, PhD

Department of Psychiatry, Chung Ang University Hospital, 120 Heukseong-ro, Dongjack-gu, Seoul 156-775, Korea

Tel: +82-2-6299-3132, Fax: +82-2-6298-1508, E-mail: hduk@yahoo.com

(a) This is an Open Access article distributed under the terms of the Creative Commons Attribution Non-Commercial License (http://creativecommons.org/licenses/bync/3.0) which permits unrestricted non-commercial use, distribution, and reproduction in any medium, provided the original work is properly cited. overloaded internal focus (OIT) and reduced attentional focus (RED).

Various research studies have looked at the association between stress and anxiety and the use of learned cognitive flexibility as a coping technique. ${ }^{47}$ Several studies suggest a relationship between stressors associated with a physical response and in the modulation of cognitive flexibility., Hillier et al. ${ }^{7}$ suggested that stressors would negatively impact performance on more complex tasks and therefore require the use of cognitive flexibility. Moreover, coping flexibility corresponding to a stressful situation has been known to be related to adaptive coping outcomes, such as psychological and physical wellbeing, social adaptation, and reduced stress. ${ }^{6}$ Based on evidence that the noradrenergic system increases cognitive flexibility, Beversdorf et al. ${ }^{5}$ suggested that cognitive flexibility in problem solving would be associated with low anxiety.

\section{Cognitive flexibility in athletes}

In sports which need coordination of several performances simultaneously, fast and effective attentional selection and quick extraction of task-relevant information from complex and dynamic sources is needed. ${ }^{8}$ As well, the ability to efficiently al- 
Table 1. Demographic characteristics (mean \pm SD)

\begin{tabular}{|c|c|c|c|}
\hline & starters $(\mathrm{N}=24)$ & nonstarters $(\mathrm{N}=46)$ & Statistics \\
\hline Age & $28.8 \pm 4.0$ & $27.1 \pm 4.3$ & $\mathrm{Z}=1.54, \mathrm{p}=0.12$ \\
\hline Education (years) & $15.0 \pm 1.7$ & $14.7 \pm 1.9$ & $\mathrm{Z}=0.61, \mathrm{p}=0.54$ \\
\hline Sports (years) & $14.7 \pm 3.9$ & $13.0 \pm 4.0$ & $\mathrm{Z}=1.70, \mathrm{p}=0.09$ \\
\hline \multicolumn{4}{|l|}{ Marital status } \\
\hline Married & 15 & 26 & \\
\hline Single & 8 & 18 & $\chi^{2}=0.24, p=0.89$ \\
\hline Divorced & 1 & 2 & \\
\hline \multicolumn{4}{|l|}{ Cognitive flexibility } \\
\hline WCST_C & $3.46 \pm 2.0$ & $2.63 \pm 1.4$ & $\mathrm{Z}=1.34, \mathrm{p}=0.18$ \\
\hline WCST_PE & $16.9 \pm 11.6$ & $27.8 \pm 13.1$ & $\mathrm{Z}=3.32, \mathrm{p}<0.01^{*}$ \\
\hline TMTA_SEC & $28.3 \pm 10.0$ & $31.2 \pm 9.2$ & $\mathrm{Z}=1.44, \mathrm{p}=0.15$ \\
\hline TMTA_error & $0.13 \pm 0.33$ & $0.04 \pm 0.21$ & $\mathrm{Z}=0.56, \mathrm{p}=0.58$ \\
\hline TMTB_SEC & $83.0 \pm 30.7$ & $101.0 \pm 33.5$ & $\mathrm{Z}=2.20, \mathrm{p}=0.03^{*}$ \\
\hline TMTB_error & $2.21 \pm 2.9$ & $2.54 \pm 3.6$ & $\mathrm{Z}=0.03, \mathrm{p}=0.97$ \\
\hline \multicolumn{4}{|l|}{ Anxiety } \\
\hline State anxiety & $37.0 \pm 6.4$ & $43.0 \pm 8.5$ & $\mathrm{Z}=2.73, \mathrm{p}<0.01^{*}$ \\
\hline Trait anxiety & $38.7 \pm 7.0$ & $41.6 \pm 10.1$ & $\mathrm{Z}=1.07, \mathrm{p}=0.29$ \\
\hline
\end{tabular}

*statistically significant. Sports: duration of athlete experience, WCST_C and PE: the number of achieved categories and perseverative errors of Wisconsin Card Sorting Test, TMTA/B_SEC \& error: time and number of errors Trail Making Test A and B

locate attention is an important factor for success in athletes. ${ }^{8}$ Casteillo and Umilta ${ }^{9}$ suggested that repetitive practice of the sport enabled athletes to allocate attention more quickly to the appropriate targets. Also, skilled athletes who adapted to rapid changes in visual information could allocate their attention more effectively than less skilled athletes. ${ }^{10}$ They were able to use visual scanning techniques as well as speed and anticipation to make changes in their performance. ${ }^{11}$

\section{Assessing cognitive flexibility with Wisconsin Card Sorting Test (WCST) and Trail Making Test (TMT)}

The Wisconsin Card Sorting Test (WCST) has been used to assess cognitive flexibility. ${ }^{2,12,13}$ Patients with prefrontal cortex (PFC) damage showed performance deficit on the WCST and other rule-switching tasks. ${ }^{14}$ The item most closely associated with cognitive flexibility in the WCST is called "perseverative" errors. Perseverative errors are those in which subjects do not follow the feedback "correct" and "wrong", but continue the previously correct rule. ${ }^{13}$

The Trail Making Test (TMT) is one of the commonly used tests for assessment of attention shifting because of its high sensitivity to the presence of cognitive impairment in minor stress and trauma. ${ }^{15}$ Motor speed and agility have been found to make a strong contribution to success on TMT. ${ }^{16}$ Actually, Rutherford et al. ${ }^{17}$ estimated athlete executive function and attention using WCST and Trail Making Test A/B in soccer athletes. Pine- da and Merchan ${ }^{18}$ also reported that WCST and TMT A/B were useful methods to assess executive function which had multiple dimensions and different cognitive operations for anticipation, goal selection, organization, planning, monitoring, shifting, controlling time, and speed, and using environmental feedback.

\section{Hypothesis}

We think that starter/non-starter athletes can be good subjects who represent high and low performance. Based on the previous studies and theory, we hypothesized that starters who have good performance skills would have better cognitive flexibility than non starters. Particularly, starters would use the technique of cognitive flexibility to lower the stress and anxiety levels throughout competition, compared to non starters.

\section{METHODS}

\section{Participants}

A total of 30 male professional-soccer athletes and 40 professional-baseball athletes were recruited. The professional-soccer and baseball athletes were all candidates in the major soccer league and major baseball league in Korea. Athletes who had a history of head injury were excluded from the study. But, we did not consider cumulative subconcussive head trauma by soccer athletes' heading play. Among the participants, the starters were 
24 athletes, and the non starters were 46 athletes (Table 1). Between those two groups, there was no difference in age, education and sports careers (Table 1).

The soccer team consisted of 36 athletes, 3 coaches and 1 manager. The final ranking of Korean soccer league 2005 was $7^{\text {th }}$ out of 14 teams. The baseball team consisted of 68 athletes, 12 coaches and 2 managers. The final ranking of the Korean baseball league 2005 was $6^{\text {th }}$ out of 8 teams. Over a 10 year period, the soccer team had a history of being a semifinal winner and the baseball team had a history of being champions, four times. All participants were volunteers. Similar to Enns and Richards ${ }^{10}$ method, the athletes were ranked into starter and non starter categories. The rankings were done by the manager and two coaches (offense and defense in soccer; hitting and fielding in baseball). These rankings included such things as dedication to training and playing ability level. When dealing with professional athletes this may be the difference between starters and non starters. This ranking was used to divide the athletes into two groups; 24 starters (11 soccer and 13 baseball athletes) and 46 non starters (19 soccer and 27 baseball). There were 10 field players and 1 goal keep in 11 soccer starters and there were 8 field players, 4 pitchers (starter, set up, long relief, and closer) and 1 designated hitter in 13 starter baseball starters. Although the manager and coaches arrived at their rankings by consensus, the experimenter and athletes remained blind to the rankings until testing was completed.

\section{Procedures}

Before the start of their respective seasons, the WCST was administered to assess cognitive flexibility. Additionally the Korean version of the STAI form Y (STAI-KY) was used to assess state and trait anxiety in both soccer and baseball athletes. Immediately before, during and after a game, visual analogue scales for stress and anxiety were completed by both soccer and baseball athletes.

The TMTA was administered after the first half of the game and the TMTB for soccer athletes was administered at the end of the game in the locker room. For baseball athletes, TMTA after the $5^{\text {th }}$ inning of the game and TMTB after the $9^{\text {th }}$ inning of the game were administered in the dugout.

\section{Tests and scales for cognitive flexibility, stress, and anxiety}

The STAI-KY was used to measure state and trait anxiety levels. ${ }^{19}$ In this scale, 40 questions measured two factors; state anxiety and trait anxiety. The reliability coefficient (Cronbach's Alpha), referring to the Korean adult normative sample, is 0.91 for state and 0.82 for trait. ${ }^{20}$

Stress and anxiety were estimated with seven point visual analogue scales for stress and anxiety which were similar to To- da's paper. $^{21}$

WCST standard 64-item version was used (CNT40R), Maxmedica Inc. '). The WCST consists of cards containing colored shapes according to one of three possible rules (color, shape, and number). If the chosen sorting rule was correct, subjects received the feedback "correct" for a placed card. After a certain number of correct trials, the sorting rule abruptly changes without notice. Thus, subjects are provided with the feedback information "wrong" and are required to change their response behavior for the next trial by choosing a relevant sorting criteria or rule, respectively. After a particular number of consecutive successful sorts, the sorting principle changes and the participant must adjust accordingly. Scores are recorded along several dimensions, with the number of categories achieved (WCST C) and the number of perseverative errors (WCST PE) committed the most commonly measured category. ${ }^{22}$ The test and retest reliability of WCST C and PE in Korean adults were 0.584 and 0.453 , respectively $(\mathrm{p}<0.05) .^{23}$

TMT A \& B consists of 25 numbers in the first trial (part A), and 13 numbers and 12 letters in the second trial (part B). The subjects draw lines on a page connecting 25 numbers consecutively as quickly as possible in part A. In Part B, the subjects must draw lines alternating between numbers and letters in consecutive order. ${ }^{24}$ Time and number of errors were scored. The test and re-test reliability of TMT A \& B reported in Korean adults were 0.62 and $0.53(\mathrm{p}<0.05) .^{25}$

\section{Statistical analysis}

Statistical analysis was performed using parametric, independent t-tests and non-parametric, Mann-Whitney $U$ test to compare the mean difference of the number of achieved categories and perseverative errors in WCST and TMT-A/B between starters and non starters. The changes of stress and anxiety during the game (start, middle, and end of game) between two groups were compared using a repeated measure ANOVA. The correlation between cognitive flexibility, stress and anxiety checked with WCST, TMT-A/B, and the visual analogue scale for stress and anxiety in starter and non starter groups were tested using Spearman correlation. All statistical analyses were performed using Statistica (Statistica version 6.0, Stat Soft).

\section{RESULTS}

\section{Demographic findings}

There was no significant differences in the age, education, athlete experience, and marital status between starters and non starters $\left(\mathrm{Z}=1.54, \mathrm{p}=0.12 ; \mathrm{Z}=0.61, \mathrm{p}=0.54 ; \mathrm{Z}=1.70, \mathrm{p}=0.09 ; \chi^{2}=\right.$ $0.24, \mathrm{p}=0.89$, respectively). Starters $(37.0 \pm 6.4)$ showed lower state anxiety than non starters $(43.0 \pm 8.5)$. There was no difference in trait anxiety between the two groups (Table 1). 


\section{The change of cognitive flexibility, stress, and anxiety during the game}

There were significant differences in perseverative errors as measured by the WCST and the time of TMTB between starters and non starters $(Z=3.32, p<0.01 ; Z=2.20, p=0.03$, respectively). The starter group had fewer perseverative errors $(Z=3.32$, $\mathrm{p}<0.01)$ and more rapid TMTB times $(\mathrm{Z}=2.20, \mathrm{p}=0.03)$, compared to the non starter group (16.9 \pm 11.6 vs. $27.8 \pm 13.1 ; 83.0 \pm$ 30.7 vs. $101.0 \pm 33.5$, respectively) (Figure 1). However, there was no statistical difference in the time of TMTA between starters and non starters $(\mathrm{Z}=1.44, \mathrm{p}=0.14)$ (Figure 1).

There were statistically significant changes in the scores of the visual analogue scale for stress and anxiety before, dur- ing, and after the game between starters and non starters ( $\mathrm{F}=4.34, \mathrm{p}=0.01 ; \mathrm{F}=6.61, \mathrm{p}<0.01$, respectively). The starter group showed mild increasing slope of stress and rapid decreasing slope of anxiety, compared to non starter (Figure 1).

\section{The correlation between cognitive flexibility, stress, and anxiety}

In the starter group, the perseverative errors measured by the WCST (WCST_PE), were correlated with state anxiety $(\mathrm{r}=0.68, \mathrm{p}<0.01)$, time as measured by the TMTA (TMTA_SEC) $(\mathrm{r}=0.44, \mathrm{p}=0.04)$, and time as measured by the TMTB (TMTB $\mathrm{SEC})(\mathrm{r}=0.45, \mathrm{p}=0.03)$. In the starter group, perseverative errors were correlated with stress at the start of the game $(r=0.77$,

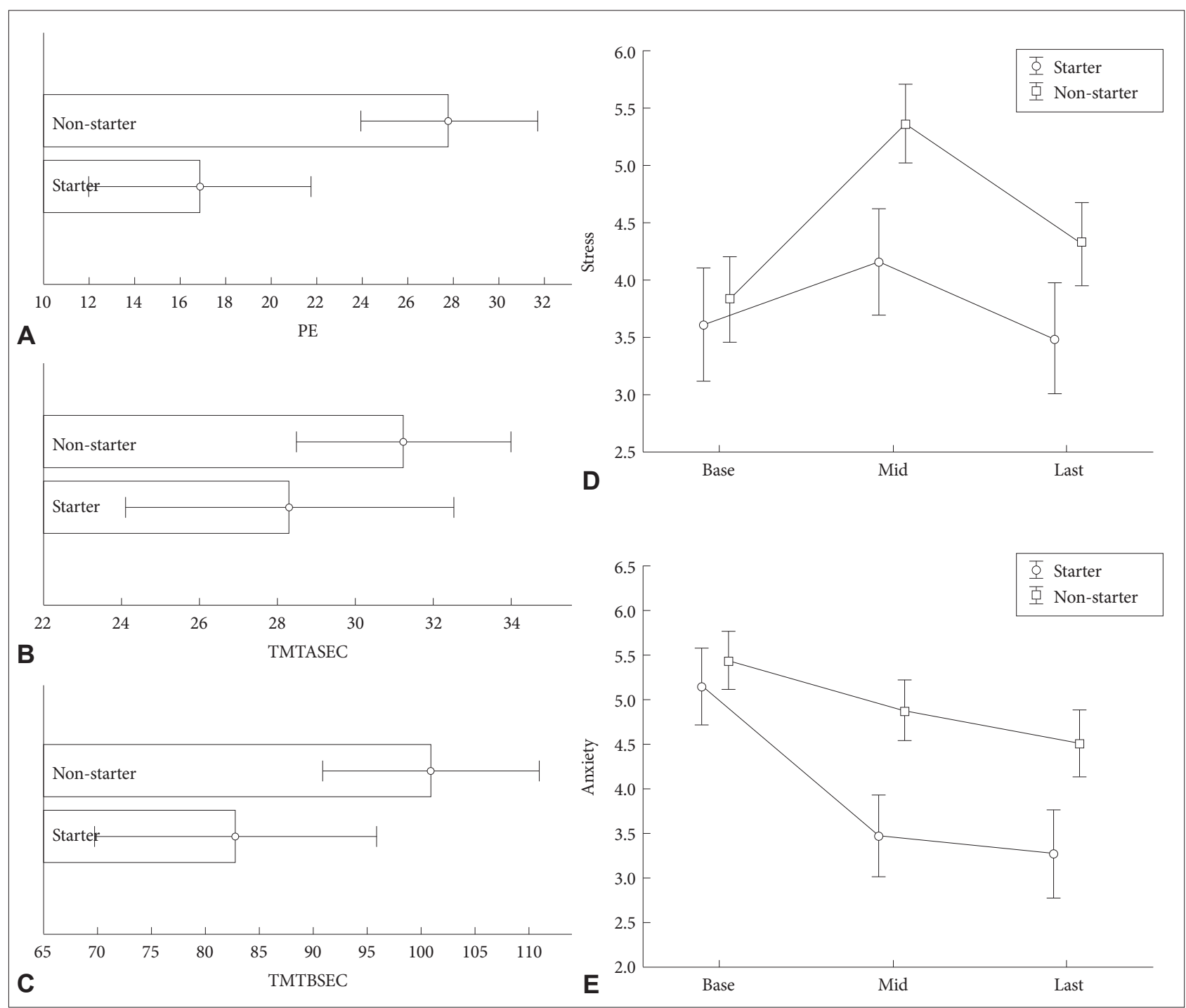

Figure 1. The change of stress, anxiety, and cognitive flexibility during competition (mean $\pm 0.95 \mathrm{C} . \mathrm{I}$.). Base, Mid, and Last: the score of stress and anxiety in start, middle, and last of game. A: Comparison of perseverative errors between Starters and non-Starters, Z=3.32, $p<0.01$. B: Comparison of TMTA-time between Starters and non-Starters, $Z=1.44, p=0.14$. C: Comparison of TMTB-time between Starters and non-Starters, $Z=2.20, p=0.03$. D: Comparison of stress between Starters and non-Starters, $F=4.34, p=0.01$. $E$ : Comparison of anxiety between Starters and non-Starters, $\mathrm{F}=6.61, \mathrm{p}<0.01$. PE: perseverative error of Wisconsin Card sorting Test, TMTA \& BSEC: Trail Making Test A and B time (second). 
$\mathrm{p}<0.01$ ), but time was not correlated with stress and anxiety during the middle of the game.

TMTB_SEC in starter group was correlated with stress and anxiety at the end of the game $(\mathrm{r}=0.66, \mathrm{p}<0.05 ; \mathrm{r}=0.42, \mathrm{p}<0.05$, respectively), while there was no significant correlation in non starter group. The stress and anxiety estimated at the end of the game was positively correlated with TMTB $\sec (\mathrm{r}=0.55, \mathrm{p}<0.01)$.

In non starter group, there was a positive correlation between WCST_PE and TMTA_SEC $(\mathrm{r}=0.31, \mathrm{p}=0.03)$. There was no significant correlation between cognitive flexibility and stress and anxiety.

\section{DISCUSSION}

\section{Cognitive flexibility in athletes}

As we hypothesized, the starter group had better cognitive flexibility and maintained it throughout the game as evidenced by lower perseverative errors and the time on the Trail Making Test (TMT Part B), compared to the non starter group. These findings are in line with previous reports. ${ }^{9,26}$ Casteillo and Umilta ${ }^{9}$ and Nougier et al. ${ }^{26}$ reported that volleyball athletes had better ability to modulate attentional resources than non-athletes. Enns and Richards ${ }^{10}$ suggested that highly skilled hockey athletes showed more flexible attentional shifting than less skilled players. In other words, highly skilled players could shorten the time of cue-target interval, which replicated the pattern seen previously. ${ }^{9,26}$ These specific findings in sports are line with those in general situations. ${ }^{27}$ Beilock et al. ${ }^{27}$ reported that the consequences of suboptimal performance, especially on examinations were associated with choking under pressure and individual differences in working memory capacity.

Different from our expectation, there was no difference in the times as measured by TMT Part A between starters and non starters. The TMT Part A times in the starter group was not correlated with either stress or anxiety in middle of the game. Those results are similar to those described by Kortte et al.'s ${ }^{28}$ study. They suggested that TMTB would be more sensitive to the deficit in cognitive flexibility than the ability to maintain a complex response set. Specifically, those results indicated that flexibility, operationalized as WCST percent perseverative errors, was the only significant predictor of Part B performance. ${ }^{28}$

\section{Stress and anxiety in athletes}

Acevedo et al. $\mathrm{s}^{29}$ suggest that higher exercise intensities for better exercise adherence and performance would make the affect of athletes more negative. That research suggests heart rate and exertion were significantly higher, and affective valence was significantly less positive ( $p>0.01$ ) for the higher-intensity, shorter duration bout, with no differences in felt arousal ( $\mathrm{p}>$ 0.05 ). Additionally, affective valence became less positive dur- ing the higher intensity bout ( $p>0.01)$ but not the lower-intensity bout ( $p>0.05) .{ }^{29}$ Current results showed that stress would increase in the middle of the game in both starters and non starters. However, the starter group demonstrated mild increasing slope of stress and rapid decreasing slope of anxiety, compared to the non starter group.

This means that the starter group controlled stress and anxiety through the game. These are not surprising results and have been reported in many studies. ${ }^{30,31}$ Hardy $^{30}$ reported that stress would debilitate the function of psychological skills (goal-setting, imagery, self-talk, and relaxation skills) which were thought to enhance the performance of athletes. In the comparison of basketball athletes with higher (debilitative) or lower (facilitative) perceptive anxiety, the facilitative athletes would be less discouraged and have less stress than debilitative athletes. ${ }^{31}$

\section{The correlation of cognitive flexibility, stress, and anxiety}

In starters, high levels of cognitive flexibility were correlated with lower stress at the start and end of the game. As mentioned in the Introduction, the modulation of cognitive flexibility and complex tasks requiring cognitive flexibility impact performance. ${ }^{4,7}$ Differentiation is the ability to recognize multiple dimensions embedded in a perceived domain and taking different perspectives when considering the domain. ${ }^{32}$ Integration is the ability to perceive trade-offs in terms of the strengths and limitations of coping strategies. ${ }^{33}$ Actually, Silva and Applebaum $^{34}$ reported that high ranking marathon runners effectively employed associative and dissociative techniques as a cognitive strategy during marathon racing.

Specifically, there was a positive correlation between stress and anxiety of starters at the end of a game. Based on the report that mental stress was associated with state anxiety, ${ }^{35}$ we cautiously suggested that cognitive flexibility in starters would control anxiety as time passed which allowed the athletes keep their play stable when confronting stressful and anxious situations.

\section{Study limitations}

First, the current study which used soccer athletes as subjects, did not consider cumulative sub-concussive head trauma when estimating cognitive function. Although there were controversies, Rutherford et al. ${ }^{17}$ suggested that the total amount of heading done by soccer athletes would affect the results of Wisconsin card sorting category. Second, there are many factors which increase the stress of athletes during exercise and competition. The relationship between stress and sports performance has been thought to be an extremely complex one and associated with the nature of the stressor, and the cognitive demands of the task being performed. ${ }^{36}$ Moreover, Deveney et al..$^{37}$ demonstrated that divergent styles of responding to emotional infor- 
mation would contribute to protection from depressed mood.

\section{Conclusion}

Current results suggested that better cognitive flexibility would enhance human performance by modulation of the anxiety and stress during competition. This study hopes to contribute substantive knowledge about the role of cognitive flexibility in the performance accompanied by stress and anxiety.

\section{REFERENCES}

1. Roth S, Cohen LJ. Approach, avoidance, and coping with stress. Am Psychol 1986;41:813-819.

2. Amos A. A computational model of information processing in the frontal cortex and basal ganglia. J Cogn Neurosci 2000;12:505-519.

3. Nideffer RM. Test of attentional and interpersonal style. J Pers Soc Psychol 1976;34:394-404.

4. Kvetnanský R, Pacák K, Sabban EL, Kopin IJ, Goldstein DS. Stressor specificity of peripheral catecholaminergic activation. Adv Pharmacol 1998;42:556-560.

5. Beversdorf DQ, Hughes JD, Steinberg BA, Lewis LD, Heilman KM. Noradrenergic modulation of cognitive flexibility in problem solving. Neuroreport 1999;10:2763-2767.

6. Cheng C. Cognitive and motivational processes underlying coping flexibility: a dual-process model. Pers Soc Psychol 2003;84:425-438.

7. Hillier A, Alexander JK, Beversdorf DQ. The effect of auditory stressors on cognitive flexibility. Neurocase 2006;12:228-231.

8. Posner MI. Orienting of attention. Q J Exp Psychol 1980;32:3-25.

9. Casteillo U, Umilta C. Orienting of attention in volleyball players. Int J Sport Psychol 1992;23:301-310.

10. Enns JT, Richards JC. Visual attentional orienting in developing hockey players. J Exp Child Psychol 1997;64:255-275.

11. Sheppard JM, Young WB. Agility literature review: classifications, training and testing. J Sports Sci 2006;24:919-932.

12. BERG EA. A simple objective technique for measuring flexibility in thinking. J Gen Psychol 1948;39:15-22.

13. Heaton RK, Chelune GJ, Talley JL, Kay GG, Curtis G. Wisconsin Card Sorting Test manual: Revised and Expanded. Psychological Assessment Resources. Odessa, FL: Psychological Assessment Resources; 1993.

14. Goldstein B, Obrzut JE, John C, Ledakis G, Armstrong CL. The impact of frontal and non-frontal brain tumor lesions on Wisconsin Card Sorting Test performance. Brain Cogn 2004;54:110-116.

15. Lezak MD. Neuropsychological assessment third edition. New York: Oxford University Press; 1995.

16. Schear JM, Sato SD. Effects of visual acuity and visual motor speed and dexterity on cognitive test performance. Arch Clin Neuropsychol 1989;4: 25-32.

17. Rutherford A, Stephens R, Potter D, Fernie G. Neuropsychological impairment as a consequence of football (soccer) play and football heading: preliminary analyses and report on university footballers. J Clin Exp Neuropsychol 2005;27:299-319.

18. Pineda DA, Merchan V. Executive function in young Colombian adults.
Int J Neurosci 2003;113:397-410.

19. Cho SC, Jung Y, Hong KE, Shin MS, Seong YH. Relationship between test-anxiety, depression, trait anxiety and state anxiety. Korean J Child Adolesc Psychiatry 2001;12:225-236.

20. Hong JY. Preoperative anxiety and information requirement in Koreans: the contributing factors of anxiety and the effect of midazolam as an anxiolytic premedication. Korean J Anesthesiol 2001;40:S1-S8.

21. Toda M, Kusakabe S, Nagasawa S, Kitamura K, Morimoto K. Effect of laughter on salivary endocrinological stress marker chromogranin A. Biomed Res 2007;28:115-118.

22. Iverson GL, Slick DJ, Franzen MD. Clinical normative data for the WCST-64 following uncomplicated mild head injury. Appl Neuropsychol 2000;7:247-251.

23. Lee JA, Shin DK, Lee CU, Lee MS. Executive function in psychiatric patient groups through Wisconsin Card Sorting Test Computer Version (WCST). J Korean Neuropsychiatr Assoc 2002;41:322-334.

24. Wagner S, Helmreich I, Dahmen h, Lieb K, Tadic A. Reliability of three alternate forms of the trail making tests A and B. Arch Clin Neuropsychol 2011;26:314-321.

25. Ha KS, Kwon JS, Lyoo IK. Development and standardization of the computerized attention assessment for Korean adults. J Korean Neuropsychiatr Assoc 2002;41:551-562.

26. Nougier V, Ripoll H, Stein JF. Orienting of attention in highly skilled athletes. Int J Sport Psychol 1989;20:205-223.

27. Beilock SL, Kulp CA, Holt LE, Carr TH. More on the fragility of performance: choking under pressure in mathematical problem solving. J Exp Psychol Gen 2004;133:584-600.

28. Kortte KB, Horner MD, Windham WK. The trail making test, part B: cognitive flexibility or ability to maintain set? Appl Neuropsychol 2002; 9:106-109.

29. Acevedo EO, Kraemer RR, Kamimori GH, Durand RJ, Johnson LG, Castracane VD. Stress hormones, effort sense, and perceptions of stress during incremental exercise: an exploratory investigation. J Strength Cond Res 2007;21:283-288.

30. Hardy L. Psychological stress, performance, and injury in sport. Br Med Bull 1992;48:615-629.

31. Wiggins MS, Cremades JG, Lai C, Lee J, Erdmann JB. Multidimensional comparison of anxiety direction and burnout over time. Percept Mot Skills 2006;102:788-790.

32. Stephan WG. Cognitive differentiation in intergroup perception. Sociometry 1977;40:50-58.

33. Suedfeld P, Coren S. Cognitive correlates of conceptual complexity. Pers Individ Diff 1992;13:1193-1199.

34. Silva JM, Appelbaum MI. Association-dissociation patterns of United States Olympic Marathon Trial contestants. Cognit Ther Res 1989;13:185192.

35. Masaoka Y, Onaka Y, Shimizu Y, Sakurai S, Homma I. State anxiety dependent on perspiration during mental stress and deep inspiration. J Physiol Sci 2007;57:121-126.

36. Jones JG, Hardy L. Stress and cognitive functioning in sport. J Sports Sci 1989;7:41-63.

37. Deveney CM, Deldin PJ. A preliminary investigation of cognitive flexibility for emotional information in major depressive disorder and nonpsychiatric controls. Emotion 2006;6:429-437. 